\title{
Differential lipid dynamics in stocked and wild juvenile lake trout
}

2

3 Madelyn G. Sorrentino ${ }^{1}$, Taylor R. Stewart ${ }^{2}$, J. Ellen Marsden ${ }^{1 *}$, and Jason D. Stockwell ${ }^{1}$

$4 \quad{ }^{1}$ Rubenstein School of Environment and Natural Resources, University of Vermont, Burlington,

5 VT, 05405, USA

$6 \quad{ }^{2}$ Department of Biology, University of Vermont, Burlington, VT, 05405, USA

7

8 *Corresponding author. Email: ellen.marsden@uvm.edu; telephone 802-598-8224; fax 802-656-

$9 \underline{8683}$ 


\section{Abstract:}

11 After more than 40 years of stocking, lake trout (Salvelinus namaycush) in Lake Champlain have

12 started to exhibit strong, natural recruitment. The abrupt surge in recruitment suggests a change

13 in limiting factors such as prey availability or overwinter survival. The distribution of juvenile

14 wild lake trout varies in relative abundance among regions of Lake Champlain. The differences

15 suggest the prey base, or foraging success, may vary geographically within the lake. Stocked and

16 wild lake trout may differ in their ability to use resources and in overwinter survival. One metric

17 that can indicate differences in resources across regions is lake trout lipid content, which reflects

18 the quality of available food and serves as an important energy reserve for overwinter survival.

19 We quantified total lipid content of stocked and wild juvenile lake trout across spatial (lake

20 regions) and temporal (seasonal) scales. No spatial differences in lipid content were apparent.

21 Wild fish had greater lipid content than stocked fish. Seasonally, stocked fish showed a

22 continuous drop in lipid content from pre-winter levels at stocking to the following autumn. Wild

23 fish showed a cyclical summer increase in lipids following winter depletion, which plateaued by

24 autumn. The high lipid content of hatchery lake trout may be necessary as they acclimate to

25 foraging in the wild. Hatcheries would benefit from evaluating whether post-stocking survival

26 could be improved by altering feeding or rearing regimes.

28 Keywords: Salvelinus namaycush, recruitment, lipids, Lake Champlain, hatchery 


\section{Introduction}

31 Lake trout (Salvelinus namaycush) was extirpated from Lake Champlain by 1900 (Plosila and

32 Anderson, 1985). Restoration efforts began in 1972 with an intensive stocking program to

33 reestablish a self-sustaining population and a recreational fishery (Marsden et al., 2010; Marsden

34 and Langdon, 2012). Successful spawning and fry emergence were documented at several sites

35 starting in 2000 but sustained natural recruitment did not begin until 2012, four decades after the

36 stocking program commenced (Marsden et al., 2018). Recent natural recruitment may be due to a

37 change in limiting factors such as food quality or quantity. For example, the Lake Champlain

38 prey base was diversified in 2003 by the invasion of alewife (Alosa pseudoharengus), a known

39 diet item of juvenile lake trout (Marsden et al. unpublished data; Madenjian et al., 2006). Winter

40 is a period of high mortality for juvenile fishes when the risks of starvation, thermal stress, and

41 predation is high (Hjort, 1914; Hurst, 2007). Increased prey availability, milder winter

42 conditions, or other factors could help juvenile lake trout survive the winter critical period.

44 Juvenile surveys indicate that relative abundance of stocked and wild lake trout varies across

45 regions of Lake Champlain. Annual stocking occurs at two highly productive spawning sites,

46 Whallon Bay in the southern Main Lake and Gordon Landing in the northern Main Lake (Ellrott

47 and Marsden, 2004). However, the highest proportion and relative abundance (catch-per-unit-

48 effort, CPUE) of wild fish has been consistently found in the central Main Lake (Marsden et al.,

49 2018; Wilkins et al. in review). The difference in expected versus observed distributions suggest

50 that prey resources may be asymmetrically distributed across the lake, unknown but productive

51 spawning sites exist in the central Main Lake, or both. 
53 An indirect measure of high foraging success, or decreased winter stress, in fishes is lipid

54 storage. Lipid content in juvenile lake trout could provide insight into the recent surge in natural

55 recruitment because of its roles in fish health - lipids serve as energy resources and help fish to

56 cope with environmental stressors (Adams, 1999; Tocher, 2003). In particular, lipids are used for

57 basic maintenance and other metabolic needs during winter, when prey availability is

58 presumably low and typically reduced by the end of the season (Adams, 1999; MacKinnon,

59 1972; Rikardsen and Elliott, 2000). For example, juvenile rainbow trout (Oncorhynchus mykiss)

60 and juvenile Atlantic salmon (Salmo salar) exhibited depleted lipid reserves (60-90\% and 34-

$6157 \%$ depletion, respectively) over winter (Biro et al., 2004; Naesie et al., 2006). Additionally, the

62 health of fish can often be predicted by lipid content; fish with low growth and condition factor

63 have correspondingly low lipid content (Amara et al., 2007). Accordingly, total lipid content

64 provides an assessment of the energy status of a fish (Naesie et al., 2006; Trudel et al., 2005),

65 and may indicate how well fish are prepared to survive the winter and how they respond to

66 winter depletion of energy reserves. Differences in lipid content may help explain why lake trout

67 in Lake Champlain are exhibiting natural recruitment and how different areas of the lake might

68 support the growth of juvenile wild fish. Variation in lipid content between stocked and wild

69 juvenile fish could also reveal differences in the abilities of wild and stocked fish to survive

70 stressors such as the winter season.

72 We hypothesized that total lipid content of wild juvenile lake trout would be greatest in the

73 central Main Lake where wild recruits are most abundant (Marsden et al., 2018; Wilkins et al. in

74 review), and would be highest in the summer when the prey base is most abundant. We also

75 hypothesized that recently stocked lake trout would have a higher lipid content than wild 
76 juveniles because hatchery fish are typically fed a highly nutritious diet under ideal conditions

77 prior to their release. However, post-release stress and adaptation to a wild-caught diet could

78 result in a substantial reduction in lipid content. To test our hypotheses, we measured total lipid

79 content of stocked and wild juvenile lake trout (ages 0-3) in Lake Champlain from three areas of

80 the Main Lake basin during three seasons, and lipid content of age-0 hatchery lake trout prior to

81 stocking.

82

\section{Methods}

84 Study System

85 Lake Champlain is situated between New York and Vermont, USA, and Quebec, Canada (Figure

86 1). The lake is $193 \mathrm{~km}$ long, with a maximum width of $20 \mathrm{~km}$. The Main Lake is meso-

87 oligotrophic, with a maximum depth of $122 \mathrm{~m}$. Since 1995 lake trout have been primarily stocked

88 at Whallon Bay, Gordon Landing, and Burlington Bay (Figure 1; Marsden et al., 2018).

\section{Sample Collection}

91 Fish were sampled at three areas in the Main Lake, near Burlington Bay, Whallon Bay, and

92 Grand Isle (hereafter referred to as the central, south, and north sites) (Figure 1). Sampling

93 efforts for juvenile lake trout have been concentrated at these locations over the past four years,

94 and provided information on variation in relative abundance of stocked and wild lake trout

95 throughout the Main Lake (Marsden et al., 2018).

96

97 Sampling was conducted between 8 June and 28 September 2018 to assess potential seasonal

98 changes in lake trout condition. The central site was sampled every 2-3 weeks, and north and 
99 south sites were each sampled twice (June and August). We used a three-in-one bottom trawl

100 with an 8-m headrope, 9.3-m footrope with chains, and 1.25-mm stretch cod end liner (Marsden

101 et al., 2018). Trawl tows were taken along-contour at depths from $28 \mathrm{~m}$ to $64 \mathrm{~m}$, with the

102 majority of tows concentrated around $40 \mathrm{~m}$, for 10 or $20 \mathrm{~min}$ at $\sim 5.5 \mathrm{~km} / \mathrm{h}$. Approximately 30

103 lake trout were selected from the trawls on each sampling date to represent the range of sizes

104 captured up to $300 \mathrm{~mm}$, and included both stocked and wild fish from each site (i.e., 15 stocked

105 and 15 wild fish). Stocked fish were identified based on presence of a fin clip (Marsden et al.

106 2018). Fish were immediately frozen on dry ice and stored at $-80^{\circ} \mathrm{C}$ until lipid extraction. A

107 sample of hatchery-reared lake trout (15 fish) was collected from the Ed Weed Fish Culture

108 Station, Grand Isle, VT, on 15 November 2018 to assess lipid content of the lake trout a week

109 prior to release into Lake Champlain. Lake trout are stocked in Lake Champlain at age-0, but are

110 reared to a size equivalent to age-1 wild fish (Marsden et al. 2018).

112 Sample Preparation

113 All lake trout were thawed and measured (total length), weighed, re-assessed for fin clips, and

114 aged based on fin clips and non-overlapping size classes. Fish were dissected and stomach

115 contents removed to avoid any influence of recently consumed prey on the estimate of total lipid

116 content. Each lake trout $>150 \mathrm{~mm}$ in total length was homogenized in a Ninja BL500

117 Professional Blender, and a 30-g subsample was removed. Lake trout $<150 \mathrm{~mm}$ in total length

118 were dried whole. Subsamples and whole small fish were dried to a constant mass at $65^{\circ} \mathrm{C}$ for 72

119 hours. Once dry, samples were ground in a mortar and pestle to produce a fine powder. 
123 Three $1-\mathrm{g}$ (for lake trout $>150 \mathrm{~mm}$ ) or $0.5-\mathrm{g}$ (for lake trout $<150 \mathrm{~mm}$ ) samples were measured

124 from the dried mass of each fish, and placed into pre-weighed 50-ml conical centrifuge tubes.

125 Samples were analyzed for total lipid content according to a modified version of the Folch et al.

126 (1957) method. Briefly, 10 or $20 \mathrm{ml}$ (depending on sample weight) of a 2:1 chloroform:methanol

127 solution was added to each centrifuge tube. Samples were agitated for 30 seconds using a vortex,

128 and centrifuged for 10 minutes at 3,000 rpm. The lipid-containing supernatant was carefully

129 pipetted off to avoid disturbing the pellet, and the process was repeated a second time. The

130 resulting pellets were then dried for $24 \mathrm{hr}$ at $65^{\circ} \mathrm{C}$ to ensure evaporation of any remaining

131 chloroform:methanol solution. Samples were weighed again in the centrifuge tubes to estimate

132 the final lipid-free dry mass measurement.

\section{Data Analysis}

135 Mean percent total lipid content (MPTLC) of the dry fish weight was determined by dividing the

136 pre-extraction weight of each sample by the post-extraction weight and converting to a percent,

137 after subtracting the weight of each centrifuge tube. The percent total lipid content of the three

138 subsamples per fish was averaged together to estimate the MPTLC for each fish. MPTLC was

139 transformed using the logit function and compared across sites (north, south, and central) and

140 seasons (spring, summer, autumn) using a two-way ANOVA. We ran interactive tests,

141 incorporating the source (stocked vs wild) variable in all analyses as a covariate, along with total

142 length as a scaling factor. A Tukey pairwise comparison was made with mcp() from the

143 multcomp package v1.4-10 in the R statistical environment v3.5.2. (Hothorn et al., 2019; R Core

144 Team, 2018). 


\section{Results}

147 A total of 197 juvenile lake trout (86 wild and 111 stocked, including 15 hatchery-sampled fish)

148 was analyzed for MPTLC. Average ( \pm SD) MPTLC content was $15.2 \pm 7.1 \%$ of dry mass for

149 stocked fish in the lake and $17.0 \pm 6.8 \%$ for wild fish. MPTLC of lake trout from the hatchery

150 was $35.1 \pm 2.9 \%$ of dry mass.

152 We found no differences in MPTLC among the three Main Lake sites $\left(\mathrm{F}_{2,175}=1.493, \mathrm{p}=0.178\right)$

153 (Figure 2). However, we did find significant differences in MPTLC between stocked and wild

154 fish $\left(\mathrm{F}_{1,175}=27.552, \mathrm{p}<0.001\right)$ (Figure 2). In the central and southern Main Lake, wild fish

155 showed significantly greater MPTLC than their stocked counterparts $\left(\mathrm{t}_{175}=3.444, \mathrm{p}=0.008\right.$ and

$156 \mathrm{t}_{175}=3.438, \mathrm{p}=0.008$, respectively).

158 Juvenile lake trout (wild plus stocked combined) from the central Main Lake varied significantly

159 in MPTLC seasonally $\left(\mathrm{F}_{2,94}=9.858, \mathrm{p}<0.001\right)$ (Figure 3). MPTLC was slightly lower in

160 summer $\left(\right.$ July - August; $\left.\left(\mathrm{t}_{94}=-2.702, \mathrm{p}=0.022\right)\right)$ and much lower in Autumn (September; $\left(\mathrm{t}_{94}=\right.$

$161-4.350, \mathrm{p}<0.001)$ ) than spring (June) for all fish. A pairwise comparison further revealed that

162 stocked fish specifically were lower in mean percent lipid content than wild fish during the

163 summer $\left(\mathrm{t}_{94}=3.209, \mathrm{p}=0.021\right)$ and autumn $\left(\mathrm{t}_{94}=2.912, \mathrm{p}=0.049\right)$.

\section{Discussion}

166 Our results were unexpected, and each of our hypotheses was refuted. First, we did not find any

167 differences in MPTLC in lake trout sampled from the three different areas of the Main Lake 
168 despite higher CPUE and higher proportions of wild lake trout in the Main Lake relative to the

169 northern and southern areas (Wilkins et al. in review). Second, wild lake trout had higher

170 MPTLC than stocked lake trout, despite a two-fold higher MPTLC in stocked lake trout just

171 prior to release into the lake. Further, the high lipid content when hatchery fish were stocked was

172 rapidly lost over their first winter in the lake, and the decline in lipid content continued over

173 summer and into autumn.

175 We expected that the spatial heterogeneity in abundance of wild juvenile lake trout in Lake

176 Champlain could be due to differences in prey quantity or quality across the different regions of

177 the Main Lake that draw juveniles from the north and south to the central lake. Alternatively,

178 lake trout hatched in the north and south could have lower survival than in the central region if

179 prey resources were higher in the central lake. However, the lack of variation in lipid content

180 among the three regions suggests that lake trout do not experience differences in prey availability

181 across the Main Lake.

183 Hatchery-reared fish are typically fed a high-ration diet rich in lipids that is reflected in their

184 body composition (Reinitz, 1983). Thus, we expected stocked juvenile lake trout would possess a

185 higher MPTLC than their wild counterparts, similar to other stocked species (e.g., Atlantic

186 salmon Salmo salar; Bergstrom, 1989). Analysis of lake trout collected from the Ed Weed Fish

187 Culture Station just prior to stocking showed that hatchery-reared lake trout had a MPTLC

188 approximately two times higher than wild lake trout of the same size in Lake Champlain.

189 However, lipid content of the newly stocked lake trout dropped markedly over their first winter

190 to the level of wild fish and continued to drop throughout summer until by autumn the stocked 
191 juvenile lake trout were lower in MPTLC than wild juvenile lake trout of the same age class,

192 although larger in size.

193

194 The high lipid content of wild compared to stocked juvenile lake trout suggests that wild lake 195 trout may be more efficient foragers than stocked fish, particularly relative to hatchery fish as

196 they adapt to seeking wild prey. The artificial environment in which stocked fish are raised may

197 not select for traits such as boldness and aggressiveness that are adaptive in natural settings

198 (Brown and Laland, 2002; Brown et al., 2003; Saikkonen et al. 2011). In general, hatchery-raised

199 fish tend to consume less food, fewer prey types, and exhibit reduced ability to switch to new

200 prey types in the wild (e.g., Saikkonen et al., 2011). Density-dependent growth and condition,

201 decreased fin quality, and inferior anaerobic capacity and swim performance have also been

202 documented for fish raised in hatcheries (McDonald et al., 1998). Hatchery-raised brook trout

203 (Salvelinus fontinalis) also exhibited lower survival rates once released compared to wild fish

204 because of poor foraging ability (Ersbak and Haase, 1983). The body of evidence suggests that

205 hatchery-raised salmonids are less efficient foragers than wild fish in a natural lake environment,

206 potentially resulting in lower lipid levels compared to wild fish, as we found in this study.

208 We also found seasonal differences in MPTLC of juvenile lake trout in the central Main Lake.

209 Summer MPTLC was slightly lower than spring lipid levels, and autumn lipid levels were much

210 lower than spring. Our findings contradict patterns reported for other piscivorous fish, where

211 lipids are usually low in the springtime after overwinter depletion, greatest in midsummer

212 months when feeding opportunities are best, and plateau by autumn when system productivity

213 drops before winter (e.g. Madenjian et al., 2000; Metcalfe et al., 2002). 
215 Stocked and wild fish showed different trends in seasonal lipid levels; the pattern in lipid content

216 in the stocked fish appeared to influence the overall trend when all fish were analyzed together.

217 Lipid content of wild fish was consistent with other salmonid fishes, in which lipids are greatest

218 in the summer and lower in spring and autumn (e.g. Madenjian et al., 2000; Metcalfe et al.,

219 2002). In summer, age-1 to 3 lake trout have access to young-of-year smelt and alewife that

220 hatch in June and July, respectively (Simonin et al 2016), and this prey base appears to be

221 sufficient to allow accumulation of lipid storage in addition to growth. Stocked fish, in contrast,

222 showed significant declines in lipid content from spring to summer to autumn. Lipid levels of the

223 hatchery fish also declined substantially between stocking in November and when they were

224 caught in spring, and decreased further through the summer into August. Although this

225 comparison was made between two cohorts (i.e., lake trout sampled prior to stocking in

226 November, and the previous cohort sampled in spring and summer of the same year), hatchery

227 conditions and diet are consistent from year to year, and we can assume reasonable consistency

228 in lake conditions in two consecutive years. The consistent seasonal decline in lipid content of

229 stocked juvenile lake trout suggests that these fish will have less energy reserves than wild

230 juveniles to survive through their second winter in the lake. The high-nutrient diet that stocked

231 lake trout were fed in the hatchery does not appear to give them a lasting advantage over wild

232 lake trout, as wild fish surpass stocked fish in lipid content by the summer following their first

233 winter in the lake. However, the high lipid content of stocked fish may be necessary for survival

234 through the first post-stocking winter, as they learn to feed on active prey and cope with stresses

235 associated with predators. 
237 Data on lipid content can improve understanding of lake trout recruitment in Lake Champlain,

238 inform stocking and conservation efforts, and support the goal of naturally reproducing fish

239 populations. Spatial differences can provide insight on the potential suitability of different areas

240 of the lake to support juvenile lake trout growth, and seasonal differences can provide insight on

241 how fish respond to winter conditions, which may impact juvenile survival rates. The lack of

242 spatial variation in lipid content suggests that the greater abundance of wild recruits in the central

243 Main Lake is not a result of higher feeding. Larger sample sizes and additional years of data

244 would be useful to confirm this result. The increase in lipid levels of wild recruits during the

245 summer is predictable and encouraging, as the data confirm that wild juvenile lake trout are

246 feeding well and therefore have high survival potential. However, we only examined juveniles

247 from June to September. Analysis of juvenile lake trout throughout the year would provide a

248 more complete picture of lipid acquisition and depletion over the winter. The dramatic loss of the

249 lipid advantage of the hatchery lake trout have at stocking is interesting; hatchery fish may be at

250 a substantial disadvantage during their first winter as they acclimate to wild conditions and

251 therefore they need the higher lipid content provided by the hatchery. However, we do not know

252 the survival rate of stocked lake trout during the first winter after stocking; the current survival

253 rate at the current high lipid content supports maintenance of an abundant population, but may

254 not be dependent on high lipid content. If survival is low, hatcheries would benefit from

255 evaluating whether survival could be improved by altering feeding or rearing regimes. We

256 propose two competing hypotheses: high lipid content either 1) provides the necessary energy

257 reserves for stocked fish to acclimate to life in the wild and learn to forage, or 2) imposes a

258 metabolic burden that cannot be sustained in the wild, and reduces the ability of stocked fish to

259 effectively secure necessary energy reserves from a wild prey base. To test these hypotheses, 
260 hatcheries could evaluate post-stocking performance and survival of lake trout raised with

261 normal and reduced hatchery diets. If the second hypothesis is supported and the first refuted,

262 hatcheries may be able to rear and stock fewer lake trout with lower ration and maintenance costs

263 to achieve the same survival level.

264

265 Acknowledgements

266 We thank Pascal Wilkins, Matthew Fidler, and Katrina Rokosz for their tireless support during

267 fish collection, and Robin Sorrentino, Grace Ireland, Samuel McClellan, and Stephen Rotella for

268 their assistance in the laboratory. We acknowledge the University of Vermont Office of

269 Fellowships, Opportunities, and Undergraduate Research for a Summer Undergraduate Research

270 Fellowship, Mini Grant, and Travel Award to MGS.

271

272 References

273 Adams, S.M., 1999. Ecological role of lipids in the health and success of fish populations., in:

274 Arts, M.T., Wainmain, B.C. (Eds.), Lipids in freshwater ecosystems. Springer, New

$275 \quad$ York, pp. 132-160.

276 Amara, R., Meziane, T., Gilliers, C., Hermell, G., Laffargue, P., 2007. Growth and condition

277 indices in juvenile sole Solea solea measured to assess the quality of essential fish

278 habitat. Mar. Ecol. Prog. Ser. 351, 201-208.

279 Bergström, E. 1989. Effect of natural and artificial diets on seasonal changes in fatty acid

280 composition and total body lipid content of wild and hatchery-reared Atlantic salmon

281 (Salmo salar L.) parr-smolt. Aquaculture 82, 205-217. 
Biro, P.A., Morton, A.E., Post, J.R., Parkinson, E.A., 2004. Over-winter lipid depletion and mortality of age-0 rainbow trout (Oncorhynchus mykiss). Can. J. Fish. Aquat. Sci. 61, 1513-1519

Brown, C., Laland, K., 2002. Social enhancement and social inhibition of foraging behaviour in hatchery $\square$ reared Atlantic salmon. Journal of Fish Biology. 61, 987-998.

Brown, C., Markula, A., Laland, K., 2003. Social learning of prey location in hatchery $\square$ reared Atlantic salmon. J. Fish Biol. 63, 738-745.

Ellrott, B.J., Marsden, J.E., 2004. Lake trout reproduction in Lake Champlain. Trans. Am. Fish. Soc. $133,252-264$.

291 Ersbak, K., Haase, B. L., 1983. Nutritional deprivation after stocking as a possible mechanism leading to mortality in stream $\square$ stocked brook trout. N. Am. J. Fish. Manag. 3, 142-151.

Folch, J., Lees, M., Sloane, S., 1957. A simple method for the isolation and purification of total lipids from animal tissues. J. Biol. Chem. 226, 497-509.

295 Hjort, J. 1914. Fluctuations in the great fisheries of Northern Europe. Rapports et Proce`sVerbaux des Re'unions du Conseil Permanent International pour l'Exploration de la Mer, Parametric Models. R package version 1.4-10.

300 Hurst, T., 2007. Causes and consequences of winter mortality in fishes. J. Fish Biol. 71, 315-345.

301 MacKinnon, J.C., 1972. Summer storage of energy and its use for winter metabolism and gonad 302 maturation in American plaice (Hippoglossoides platessoides). J. Fish. Res. Bd. Can. 29, 1749-1759. 
Madenjian, C.P., Elliott, R.F., DeSorcie, T.J., Stedman, R.M., O'Connor, D.V., Rottiers, D.V., 2000. Lipid concentrations in Lake Michigan fishes: Seasonal, spatial, ontogenetic, and long-term trends. J. Great Lakes Res. 26, 427-444.

Madenjian, C.P., Holuszko, J.D., Desorcie, T.J., 2006. Spring-summer diet of lake trout on Six Fathom Bank and Yankee Reef in Lake Huron. J. Great Lakes Res. 32, 200-208.

Marsden, J.E., Chipman, B.D., Pientka, B., Schoch, W.F., Young, B.A., 2010. Strategic plan for

Marsden, J.E., Langdon, R.W. 2012. The history and future of Lake Champlain's fishes and fisheries. J. Great Lakes Res. 38, 19-34.

Marsden, J.E., Kozel, C.L., Chipman, B.D. 2018. Recruitment of lake trout in Lake Champlain. J. Great Lakes Res. 44, 166-173.

Metcalfe, N.B., Bull, C.D., Mangel, M., 2002. Seasonal variation in catch-up growth reveals state-dependent somatic allocations in salmon. Evol. Ecol. Res. 4, 871-881.

324 Plosila, D.S., Anderson, J.K., 1985. Lake Champlain Salmonid Assessment Report. Fisheries class content as an indicator of critical periods for survival in juvenile Atlantic salmon Technical Committee, Lake Champlain Fish and Wildlife Management Cooperative, Essex Junction, VT (124 pp.). 
327 Reinitz, G., 1983. Influence of diet and feeding rate on the performance and production cost of

328 rainbow trout. Trans. Am. Fish. Soc. 112, 830-833.

329 R Core Team., 2018. R: A language and environment for statistical computing. R Foundation for

330 Statistical Computing, Vienna, Austria. URL https://www.R-project.org/.

331 Rikardsen, A.H., Elliott, J.M., 2000. Variations in juvenile growth, energy allocation and lifehistory strategies of two populations of Arctic charr in North Norway. J. Fish Biol. 56, 328-346.

334 Saikkonen, A., Kekalainen, J., Piironen, J., 2011. Rapid growth of Atlantic salmon juveniles in captivity may indicate poor performance in nature. Biol. Conserv. 144, 2320-2327.

336 Simonin, P.W., Parrish, D.L., Rudstam, L.G., Sullivan, P.J., Pientka, B., 2012. Native rainbow smelt and nonnative alewife distribution related to temperature and light gradients in

Tocher, D.R., 2003. Metabolism and functions of lipids and fatty acids in teleost fish. Rev. Fish.

$340 \quad$ Sci. $11,107-184$.

341 Trudel, M., Tucker, S., Morris, J.F.T., Higgs, D. A., Welch, D. W., 2005. Indicators of energetic status in juvenile coho salmon and Chinook salmon. N. Am. J. Fish. Manag. 25, 374-390.

343 Wilkins, P.D., Marsden, J. E. In review. Spatial and seasonal comparisons of growth of wild and 344 stocked juvenile lake trout in Lake Champlain. J. Great Lakes Res. 5-22-2019 


\section{Figure Captions}

Figure 1: Lake Champlain, showing sampling sites in the Main Lake and two major known lake trout spawning sites at Gordon Landing and Burlington Bay.

Figure 2: Spatial comparison of mean percent total lipid content of the dry weight of juvenile lake trout ages 1-3 in Lake Champlain captured between 8 June and 29 September 2019. Grey bars denote stocked (fin-clipped) lake trout, and white bars denote wild (unclipped) lake trout. Error bars show standard error. Sample size is indicated at the base of each data bar. North, central, and south refer to the sampling regions in the Main Lake basin.

Figure 3: Seasonal comparison of mean percent total lipid content of the dry weight of juvenile lake trout ages 0-3 in Lake Champlain captured between 8 June and 29 September 2019. Grey bars denote stocked (fin-clipped) lake trout, and white bars denote wild (unclipped) lake trout. Error bars show standard error. Sample size is indicated at the base of each data bar. The seasons refer to the month in which lake trout were captured: June (spring), July - August (summer), September (autumn), and a November sample from the Ed Weed Fish Culture Station (prewinter). We refer to the hatchery sample as pre-winter for comparison between pre-winter and post-winter (i.e., spring) fish. 


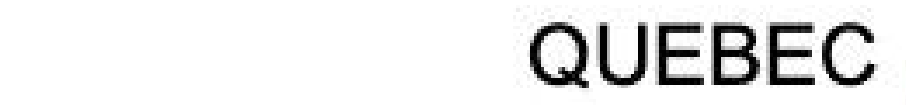

NEW

YORK

North

\section{Gordon Landing}

VERMONT

Central- $\{0\}$ Burlington

South $\{$. Whallon Bay 


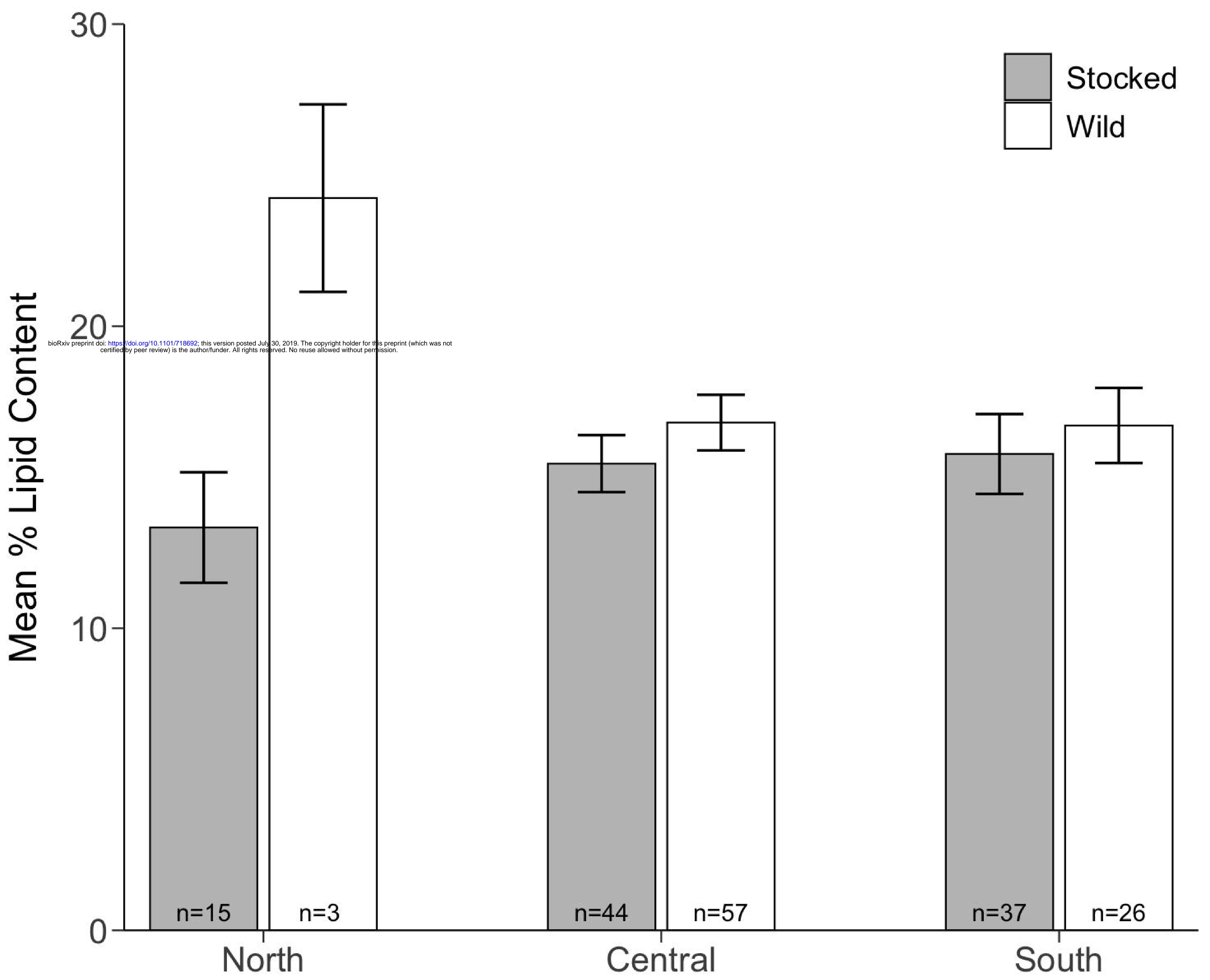


